\title{
EXCESS THERMODYNAMIC AND ACOUSTIC PROPERTIES FOR EQUIMOLAR MIXTURE OF METHYL BENZOATE AND ALKANOLS WITH BENZENE AT 303.15 K
}

\author{
Sk. Suriya Shihab ${ }^{1}$, K. Govinda Rao ${ }^{2}$, M. Gnana Kiran², Shaik. Babu, ${ }^{2, *}$ \\ and S. Sreehari Sastry ${ }^{1}$ \\ ${ }^{1}$ Department of Physics, Acharya Nagarjuna University, Nagarjunanagar -522510, India. \\ ${ }^{2}$ Department of Physics, K L University, Guntur- 522 502, Andhra Pradesh, India. \\ *E-mail: babu.computers@gmail.com
}

\begin{abstract}
The values of speed of sound $(\mathrm{U})$, density $(\rho)$ and viscosity $(\eta)$ of pure liquids and the mixture of methyl benzoate + 1-propanol/1-butanol/1-pentanol with benzene were measured over the entire mole fraction range at $\mathrm{T}=303.15 \mathrm{~K}$. From these values, various thermo-acoustic parameters such as excess molar volume $\left(\mathrm{V}^{\mathrm{E}}\right)$, excess isentropic compressibility $\left(\mathrm{K}_{\mathrm{s}}^{\mathrm{E}}\right)$, and excess free length $\left(\mathrm{L}_{\mathrm{f}}^{\mathrm{E}}\right)$, excess Gibbs free energy $\left(\Delta \mathrm{G}^{*} \mathrm{E}\right)$ and excess enthalpy $\left(\mathrm{H}^{\mathrm{E}}\right)$ are calculated. The reason for deviations in these excess parameters is explained based on the intermolecular interactions present in these liquids.
\end{abstract}

Keywords: methyl benzoate, density, 1-alkanols, acoustic properties, the speed of sound.

() RASĀYAN. All rights reserved

\section{INTRODUCTION}

The speed of sound investigations along with the volumetric and viscometric studies of pure liquids and their liquid mixtures are of considerable importance. They find extensive applications in many industries ${ }^{1,2}$. Several researchers ${ }^{3-9}$ have measured the density, viscosity, and speed of sound for a wide range of liquids, their binary and ternary mixtures. Alcohols are strongly associated in solution because of dipole-dipole interaction and hydrogen bonding. They are of great importance for their relevant role in chemistry, biology, and studies on hydrogen bonding in liquid mixtures. Alcohols are widely used as solvents. The molecules containing $-\mathrm{OH}$ group form associative liquids due to hydrogen bonding. The effect shown by the molecules with other functional groups on these molecules plays an important role in understanding the behavior of hydrogen bonding. The investigations regarding the molecular association in liquid mixtures having an aromatic group as one of the components are of particular interest since the aromatic group is highly non-polar and can associate with any other group having some degree of polar attractions. The study of thermodynamic properties of multicomponent liquid mixtures and data on the analysis in terms of various models are important for industrial and pharmaceutical applications ${ }^{10}$. The excess thermodynamic functions ${ }^{11}$ are sensitively dependent not only on the differences in intermolecular forces but also on the differences in the size of the molecules. The signs and magnitudes of these excess values can throw light on the strength of interactions. So in continuation of our previous work ${ }^{3}$, from the experimentally determined values of speed of sound density and viscosity, various thermo-acoustic parameters like excess isentropic compressibility $\left(K_{\mathrm{s}}^{\mathrm{E}}\right)$, excess molar volume $\left(V^{\mathrm{E}}\right)$, excess free length $\left(L_{\mathrm{f}}^{\mathrm{E}}\right)$, excess Gibbs free energy $\left(\Delta G^{*}\right)$ and excess enthalpy $\left(H^{\mathrm{E}}\right)$ have been calculated. The intermolecular interactions have been estimated in the light of these excess parameters.

\section{Computational Details}

\section{EXPERIMENTAL}

The values of density, viscosity and speed of sound for the mixtures of 1-alkanols and methyl benzoate with benzene at $303.15 \mathrm{~K}$ over the entire mole fraction range were measured ${ }^{3}$. Here we have calculated the excess 
values of isentropic compressibility and free length values to check the applicability of the ideal mixing rules to the components under study. The excess values of isentropic compressibility $K_{\mathrm{s}}{ }^{\mathrm{E}}$ were calculated as follows,

$$
K_{\mathrm{s}}^{\mathrm{E}}=K_{\mathrm{s}}-K_{\mathrm{s}}^{\mathrm{id}}
$$

Where the calculated value of isentropic compressibility for the mixture is represented with $\mathrm{K}_{\mathrm{s}}$

$$
K_{s}=\frac{1}{\rho U^{2}}
$$

$\mathrm{K}_{s}{ }^{\mathrm{E}}$ is its excess value and $\mathrm{K}_{s}{ }^{\text {id }}$ is the ideal isentropic compressibility value for an ideal mixture which was calculated from the relation recommended by Benson and Kiyohara ${ }^{12,13}$ and Douheret et al. ${ }^{14}$.

$$
K_{\mathrm{s}}^{\mathrm{id}}=\sum \phi_{\mathrm{i}}\left\{K_{\mathrm{s}, \mathrm{i}}^{\mathrm{o}}+\frac{T V_{\mathrm{i}}^{\mathrm{o}}\left(\alpha_{\mathrm{i}}^{\mathrm{o}}\right)^{2}}{C_{\mathrm{p}, \mathrm{i}}^{\mathrm{o}}}\right\}-T\left(\sum x_{\mathrm{i}} V_{\mathrm{i}}^{\mathrm{o}}\right)\left(\frac{\sum \phi_{\mathrm{i}} \alpha_{\mathrm{i}}^{\mathrm{o} 2}}{\sum x_{\mathrm{i}} C_{\mathrm{p}, \mathrm{i}}^{\mathrm{o}}}\right)
$$

in the above expression $K_{\mathrm{s}, \mathrm{i}}^{\mathrm{o}}, V_{\mathrm{o}}^{\mathrm{i}}, \alpha_{\mathrm{i}}^{\mathrm{o}}, C_{\mathrm{p}, \mathrm{i}}^{\mathrm{o}}$ are the isentropic compressibility, molar volume, isobaric thermal expansion coefficient and molar isobaric heat capacity of pure component $i, T$ represents temperature, $\phi_{i}$ is the volume fraction and $x_{i}$ represents the mole fraction of $i$ in the mixture. The density values have been used to calculate the excess volumes, $\mathrm{V}^{\mathrm{E}}$, using the equation,

$$
V^{E}=\frac{x_{1} M_{1}+x_{2} M_{2}}{\rho}-\left(\frac{x_{1} M_{1}}{\rho_{1}}+\frac{x_{2} M_{2}}{\rho_{2}}\right)
$$

here $\rho$ is the density of the mixture and $\mathrm{x}_{1}, \mathrm{M}_{1}$, and $\rho_{1}$ and $\mathrm{x}_{2}, \mathrm{M}_{2}$, and $\rho_{2}$ are the mole fraction, molar mass, and density of pure components 1 and 2 , respectively.

The excess values of free length $\left(\mathrm{L}_{\mathrm{f}}^{\mathrm{E}}\right)$, Gibbs free energy $\left(\Delta \mathrm{G}^{* \mathrm{E}}\right)$ and enthalpy $\left(\mathrm{H}^{\mathrm{E}}\right)$ were calculated by using the expressions given in literature ${ }^{15}$ as follows,

$$
\mathrm{L}_{\mathrm{f}}^{\mathrm{E}}=\mathrm{L}_{\mathrm{f}}-\mathrm{K}_{\mathrm{T}}\left(\mathrm{K}_{\mathrm{s}}^{\mathrm{id}}\right)^{1 / 2}
$$

Where $\mathrm{L}_{\mathrm{f}}$ is the calculated value for the mixture and $\mathrm{K}_{\mathrm{T}}$ represent a temperature dependent constant whose value is $\mathrm{K}_{\mathrm{T}}=(91.368+0.3565 \mathrm{~T}) \times 10^{-8}$.

Excess Gibbs free energy of activation $\Delta \mathrm{G}^{*} \mathrm{E}$ was calculated as follows,

$$
\Delta G^{* \mathrm{E}}=R T\left[\ln \left(\frac{\eta V}{\eta_{2} V_{2}}\right)-x_{1} \ln \left(\frac{\eta_{1} V_{1}}{\eta_{2} V_{2}}\right)\right]
$$

Where $R$ is the perfect gas constant, $T$ is absolute temperature, $\eta$ is the viscosity of the mixture and $\eta_{1}, \eta_{2}$ are the viscosities of the pure compounds, $\mathrm{V}$ is the molar volume of mixture and $\mathrm{V}_{1}, \mathrm{~V}_{2}$ are the molar volumes of the pure compounds, Excess enthalpy $\mathrm{H}^{\mathrm{E}}$ was calculated from usual relation.

$$
H^{E}=H-\left(x_{1} H_{1}+x_{2} H_{2}\right)
$$

In the above expression $\mathrm{H}$ represents the calculated value of enthalpy for the mixture and $\mathrm{H}_{1}, \mathrm{H}_{2}$ represent enthalpy of pure components 1 and 2, respectively.

\section{RESULTS AND DISCUSSION}

From the measured values of density, the speed of sound and viscosity ${ }^{1}$, the values of excess isentropic compressibility $\left(\mathrm{K}_{\mathrm{s}}^{\mathrm{E}}\right)$, excess molar volume $\left(\mathrm{V}^{\mathrm{E}}\right)$, excess free length $\left(\mathrm{L}_{\mathrm{f}}^{\mathrm{E}}\right)$, excess Gibbs free energy $\left(\Delta \mathrm{G}^{* \mathrm{E}}\right)$ and excess enthalpy $\left(\mathrm{H}^{\mathrm{E}}\right)$ were calculated. These excess parameters were drawn against mole fractions separately at $\mathrm{T}=303.15 \mathrm{~K}$ shown in Figures $1-5$. The deviations observed in the excess parameters indicate the strength of interactions present between the component molecules of these mixtures under study ${ }^{16}$. The variations in these excess parameter values reflect the interactions between the mixing species, depending upon the composition, molecular sizes, and shapes of the components and temperature.

The excess isentropic compressibility $\left(\mathrm{K}_{\mathrm{s}}^{\mathrm{E}}\right)$ for the liquid mixtures under study are as shown in figure 1 . It can be observed that the $\mathrm{K}_{\mathrm{s}}^{\mathrm{E}}$ values are positive over the entire mole fraction range indicating the presence of weak interactions in these mixtures and also that the molecules are loosely packed in the mixtures due to their shape and size. The liquids having different molecular sizes and shape mix well thereby reducing 
the volume which causes the values of $\mathrm{K}_{\mathrm{s}}{ }_{\mathrm{E}}^{\mathrm{E}}$ to be negative and if the liquids are of almost same size then they do not mix well and there is a lot of free space in between as suggested by Fort and Moore ${ }^{17}$. So, it can be said that the molecular interactions are weak in these liquid mixtures and that the medium is loosely packed.

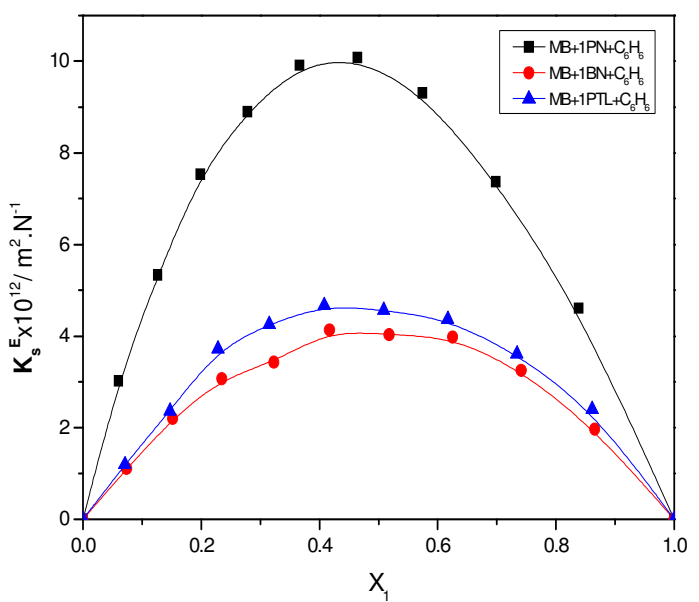

Fig.-1: Excess isentropic compressibility with respect to mole fraction at $303.15 \mathrm{~K}$ for $\mathbf{m}$, Methyl benzoate + 1-propanol +benzene; $\bullet$, Methyl benzoate +1 -butanol +benzene; $\boldsymbol{\Delta}$,Methyl benzoate+1-pentanol + benzene.

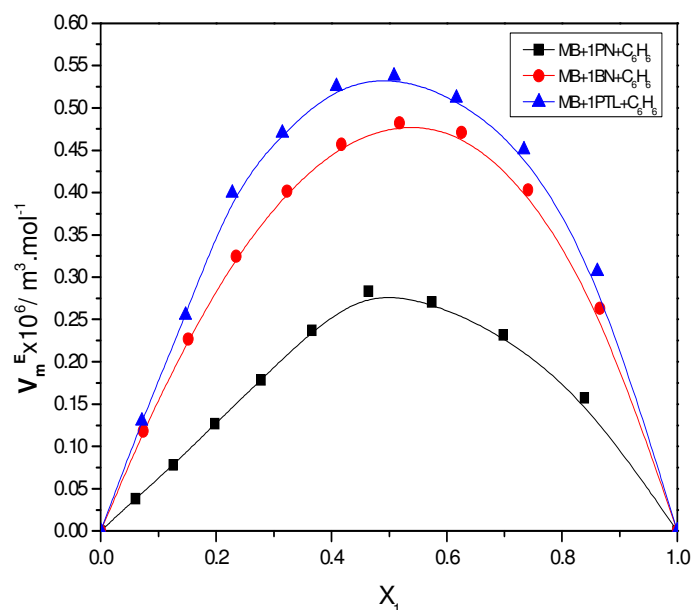

Fig.-2: Excess molar volume with respect to mole fraction at $303.15 \mathrm{~K}$ for $\mathbf{m}$,Methyl benzoate+1propanol+benzene; $\bullet$, Methyl benzoate +1 -butanol +benzene; $\boldsymbol{\Delta}$,Methyl benzoate+1-pentanol+ benzene.

The nature of the intermolecular interactions in liquid mixtures can be explained by the variation of excess molar volume $\left(\mathrm{V}^{\mathrm{E}}\right)$, with respect to mole fraction, $x_{1}$, as shown in Figure 2 at $\mathrm{T}=303.15 \mathrm{~K}$. The expansion in molar volume can be attributed to the presence of weak forces of attraction ${ }^{18}$ between the molecules. Similar results were reported by Garcia et $\mathrm{al}^{19}$. The negative values of $\mathrm{V}^{\mathrm{E}}$ indicate that there is more compact packing of molecules which implies that the molecular interactions are strong whereas the positive values indicate a loose packing of molecules in the mixture compared to those in the pure component. Similar results were observed by earlier workers ${ }^{20}$.

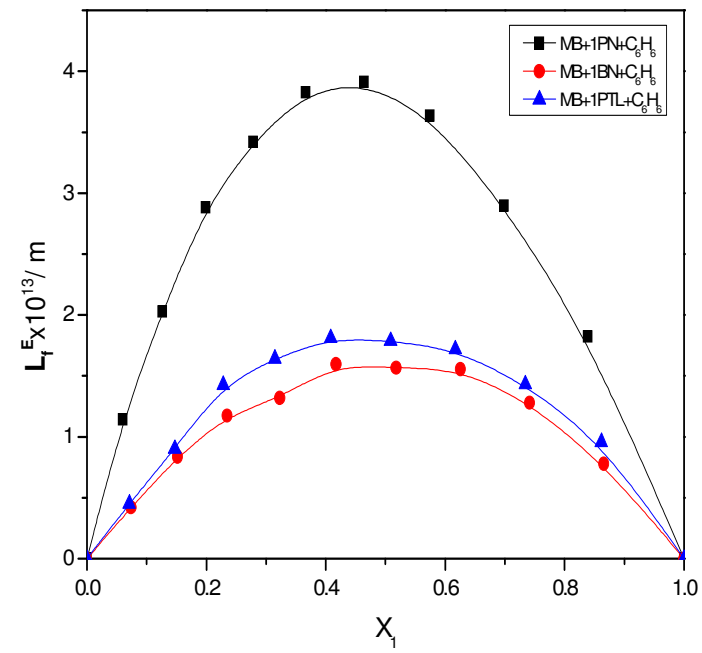

Fig.-3: Excess intermolecular free length with respect to mole fraction at $303.15 \mathrm{~K}$ for $\mathbf{m}$, Methyl benzoate +

1-propanol +benzene; $\bullet$, Methyl benzoate+ 1 butanol+benzene; $\boldsymbol{\Lambda}$, Methyl benzoate+ 1pentanol+benzene.

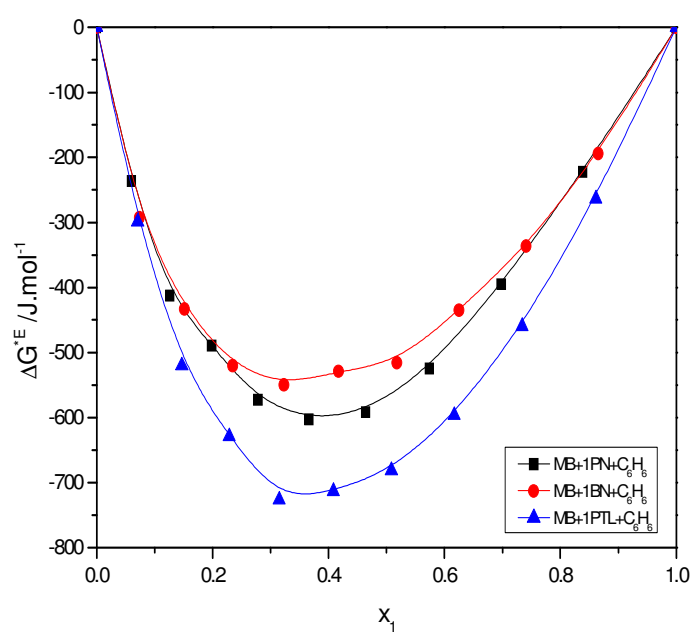

Fig.-4: Excess Gibbs free energy with respect to mole fraction at $303.15 \mathrm{~K}$ for $\mathbf{m}$, Methyl benzoate +1 propanol +benzene; $\bullet$, Methyl benzoate +1 butanol+benzene; $\boldsymbol{\Lambda}$, Methyl benzoate+ 1pentanol+benzene. 
It can be observed from Figure 3 that the $\mathrm{L}_{\mathrm{f}}^{\mathrm{E}}$ values are positive which suggest that specific interactions are not present between unlike molecules in these systems ${ }^{21}$.From figure- 4 the excess Gibbs free energy of activation $\left(\Delta \mathrm{G}^{*} \mathrm{E}\right)$ can be observed, where the values are negative over the entire range of mole fraction. These negative values indicate the existence of a weak intermolecular interaction between the component molecules of the liquid mixtures under study.Tthe bond formation strength in Methyl benzoate+1pentanol+benzene system is less compared to that of another system, this is indicated by the maximum deviation observed in $\Delta \mathrm{G}^{* \mathrm{E}}$. Similar results were observed by earlier workers. ${ }^{22}$

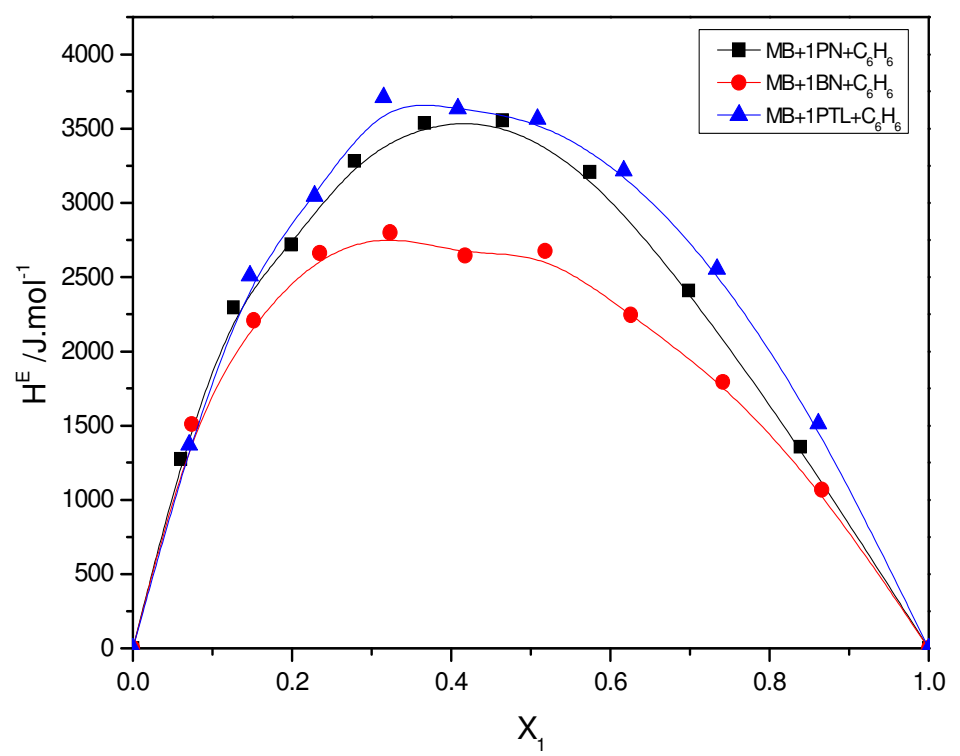

Fig.-5: Excess enthalpy with respect to mole fraction at 303.15K for $\mathbf{m}$,Methyl benzoate +1 -propanol + benzene; $\bullet$, Methyl benzoate + 1-butanol+benzene; $\boldsymbol{\Lambda}$, Methyl benzoate + 1-pentanol+benzene.

At $\mathrm{T}=303.15 \mathrm{~K}$ the excess values of Enthalpy $\left(\mathrm{H}^{\mathrm{E}}\right)$ are positive as shown in figure 5 with respect to the mole fraction, $\mathrm{x}_{1}$. With the increase in alkanol chain length, the positive values of $\mathrm{H}^{\mathrm{E}}$ also increase, this is a clear indication that there are dispersion forces between molecules in this liquid mixtures ${ }^{23}$. It also suggests the existence of weak dipole-dipole interactions in these systems.

All the above-discussed parameters, confirm the presence of hydrogen bonding between the compounds in these mixtures. Because of the increased chain length, the strength of bond formation between the compounds in the present mixtures decrease. Also, the excess values correlate with one another and also supports the formation of hydrogen bonding in these liquid mixtures.

\section{CONCLUSION}

The values of $K_{\mathrm{S}}^{\mathrm{E}}, V^{\mathrm{E}}, L_{\mathrm{f}}^{\mathrm{E}}, \Delta G^{* \mathrm{E}}$ and $H^{\mathrm{E}}$ were computed from the measured values of density, the speed of sound and viscosity. Thus by studying the variations in these parameters, the formation of hydrogen bond between the mixtures is identified. Positive values were observed in the case of excess isentropic compressibility, excess molar volume, excess free length and excess enthalpy, while negative values were obtained in excess Gibbs free energy of activation. The presence of weak bonding between the component molecules can be confirmed with these values. Apart from the above-said values/reasons, the difference in molar masses of the liquid molecules is also responsible for the non-existence of specific interactions.

\section{REFERENCES}

1. S.L. Oswal, P. Oswal and R.P. Shalak, J. Solution Chem., 27, 507 (1998).

2. H. Kumar, M. Kaur, R. Gaba and K.Kaur, J. Therm. Anal. Calorim., 105, 1071 (2011). 
3. Sk. Suriya Shihab, Shaik. Babu and S.Sreehari sastry, Rasayan J. Chem., 9(4), 641 (2016).

4. H. Salhi, Shaik.Babu, A.A. Al-Arfaj, M.A. Alkhaldi, N.O. Alzamel, S. Akhtar, N. Ouerfelli, Rasayan J. Chem., 9(4), 864 (2016).

5. H. Salhi, Shaik. Babu, N. Al-Eidan, N.H. Mekni, N. Al-Otaibi, K.Y. Alqahtani, N.A. Al-Omair, N. Ouerfelli, Mediterr J.Chem., 6(2), 33 (2017).

6. Shaik.Babu, S. V. Kumara Sastry, Ha.Sie Tiong, S.Sreehari Sastry, E-J. chem., 9(4), 2309 (2012).

7. Shaik.Babu, Int. J. Chem. Conc., 1(2), 81 (2015).

8. Shaik.Babu, E-J. Chem., 8(S1) S330 (2011).

9. S. Sreehari sastry, S.M. Ibrahim, L. Tanuj Kumar, Shaik.Babu and Ha. Sie Tiong, Int. J. Eng. Res. Tech., 4, 315 (2015).

10. J.M. Resa, C. Gonzalez, J.M. Goenaga and M. Iglesias, J. Therm Anal. Calorim., 87, 237 (2007).

11. S. Sharma, B. Jasmin, J. Ramani and R. Patel, Phys. Chem. Liq., 49, 765 (2011).

12. O. Kiyohara and G.C. Benson, J. Chem.Thermodyn., 11, 861 (1979).

13. G.C. Benson and O. Kiyohara, J. Chem.Thermodyn., 11, 1061 (1979).

14. G. Douheret, A. Pal and M. I. Davis, J. Chem. Thermodyn.. 22, 99 (1990).

15. S.S. Sastry, S. Babu, T. Vishwam, K. Parvateesam and H.S. Tiong, Physica B., 420, 40 (2013).

16. J.D. Pandey, R. D. Rai, R. K. Shukla, A.K. Shukla and N. Mishra, Indian J. Pure Appl. Phys., 31,84 (1993).

17. R.J. Fort and W.R. Moore, Trans. Farad. Soc., 61, 2102 (1965).

18. S.C. Bhatia, R. Rani, R. Bhatia and H. Anand, J. Chem. Thermodyn., 43, 479 (2011).

19. S. Sreehari sastry, Shaik.Babu, T. Vishwam and Ha. Sie Tiong, J. Chem. Thermodyn., 68, 183 (2014).

20. S. Sreehari sastry, Shaik.Babu, T. Vishwam and Ha. Sie Tiong, J. Therm. Anal. Calorim., 116, 923 (2014).

21. S.V.Kumara Sastry, Shaik.Babu, Ha.Sie Tiong, S.Sreehari Sastry. Res. J. Pharm., Biol. Chem. Sci., 3(2), 500 (2012).

22. S.V.Kumara Sastry, Shaik.Babu, Ha.Sie Tiong, S.Sreehari Sastry, J. Chem. Pharm. Res., 4(4), 2122 (2012).

23. S. Sreehari sastry, Shaik.Babu, T. Vishwam and Ha.Sie Tiong, Phys. Chem. Liq., 52, 272 (2014).

[RJC-1552/2017] 